\title{
Experimental study on the emission influence of the fuel system faults for light-duty vehicle
}

\author{
Le Liu ${ }^{1, *}$, Lihui Wang ${ }^{1}$, Liyun Qian ${ }^{2}$, Peilin Geng ${ }^{1}$, Wei Zhao ${ }^{1}$, and Jingyuan $\mathrm{Li}^{1}$ \\ ${ }^{1}$ China Automotive Technology and Research Center Co., Ltd., Tianjin 300300, China \\ ${ }^{2}$ China Research Academy of Environmental Sciences VECC, China
}

Keywords: light-duty vehicle, fuel system, fault diagnosis, emission.

\begin{abstract}
The fuel system is a very important system in light-duty vehicles. The faults of the system will cause serious deterioration of vehicle emissions and other performance. In order to study the influence of different types of faults on emissions, this paper studies the faults of several OBDII vehicles. The results show that: the fault of rich mixture in fuel system will increase the emissions of $\mathrm{CO}$ and NMHC by 3-5 times and the emissions of NOx by 1-2 times; the fault of lean mixture in fuel system will increase the emissions of NOx by 4-5 times and the emissions of $\mathrm{CO}$ and NMHC by 0.7-2.5 times; there are two kinds of imbalance faults, one is imbalance lean and the other is imbalance rich. Imbalance lean mainly causes NOx deterioration, which is increased by 7.5 times. Imbalance rich mainly causes $\mathrm{CO}$ and $\mathrm{NMHC}$ emissions deterioration, which is increased by about 3 times. There are many kinds of faults in the fuel system which cause serious deterioration of emissions. It is necessary to focus on monitoring the faults of the fuel system.
\end{abstract}

\section{Introduction}

Since the 1980s, the United States has added OBD diagnostic items to the automobile emission regulations, and revised the OBD diagnostic item standards in the 1990s, forming a relatively complete OBD II standard [1, 4-7], which can effectively monitor the system function faults that have a great impact on vehicle emissions, so as to effectively control the emissions during the actual use of the vehicle, and facilitate the timely maintenance of the vehicle.

At the beginning of this century, Europe and China began to learn the emission standards of OBDII, and incorporated some basic OBD diagnosis projects into the emission standards of Europe and China ${ }^{[5-7]}$. After more than ten years of practical application, the defects of the national five-year OBD standard gradually appear.

The requirements of OBD diagnosis project in the Fifth Five Year Plan of China are vague, and only the diagnosis of individual systems is clearly described in the standard, but the diagnosis of most other emission control systems such as fuel system is classified as "other emission systems" ${ }^{[3]}$, which faults of these systems need to be monitored by OBD,

\footnotetext{
* Corresponding author: liule@catarc.ac.cn
} 
which is not clearly described in the standard, so that the vehicle emission monitoring agencies and vehicle manufacturers are very It is difficult to have a clear basis for the implementation of the standard, which has caused many ambiguities and great difficulties for the implementation of the standard. See Table $1^{[1,3]}$ for specific differences.

Table 1. Differences in OBD standards.

\begin{tabular}{|c|c|c|}
\hline Diagnostics & OBD-II & E-OBD and China 5 OBD \\
\hline Catalytic converter & deterioration, $50 \% \mathrm{NMHC}$ & Deterioration \\
\hline Misfire & Single or multi-cylinder misfire & $\begin{array}{l}\text { Similarity, but deleting the specific } \\
\text { requirements }\end{array}$ \\
\hline Oxygen sensor & $\begin{array}{l}\text { Slow response, delay, electric } \\
\text { circuit diagnosis }\end{array}$ & $\begin{array}{l}\text { Faults influencing emissions, only } \\
\text { a few specific requirements }\end{array}$ \\
\hline $\begin{array}{l}\text { Heating } \\
\text { converter }\end{array}$ & Heating function fault & No specific requirements \\
\hline Evaporation system & $\begin{array}{l}0.5 \mathrm{~mm}, 1 \mathrm{~mm} \text { and desorption } \\
\text { gas flow fault }\end{array}$ & Disconnected desorption valve \\
\hline Fuel system & Too rich or lean and imbalance & $\begin{array}{l}\text { No specific requirements, } \\
\text { emission-related fault }\end{array}$ \\
\hline $\begin{array}{l}\text { Cold start emission } \\
\text { reduction strategy }\end{array}$ & $\begin{array}{l}\text { Emission reduction strategy } \\
\text { fault }\end{array}$ & No requirements \\
\hline Cooling system & $\begin{array}{l}\text { Thermostat or temperature } \\
\text { sensor fault }\end{array}$ & $\begin{array}{l}\text { No specific requirements, } \\
\text { emission-related fault }\end{array}$ \\
\hline EGR & $\begin{array}{l}\text { EGR flowrate being too high or } \\
\text { low }\end{array}$ & $\begin{array}{l}\text { No specific requirements, } \\
\text { emission-related fault }\end{array}$ \\
\hline VVT & $\begin{array}{l}\text { Target standards error and slow } \\
\text { response }\end{array}$ & No requirements \\
\hline Air conditioning system & Strategy failure & No requirements \\
\hline DOR & $\begin{array}{l}\text { Attenuation of emission } \\
\text { reduction effects }\end{array}$ & No requirements \\
\hline $\mathrm{PCV}$ & Disconnect pipeline fault & No requirements \\
\hline Secondary air & $\begin{array}{lll}\begin{array}{l}\text { Function, } \\
\text { diagnosis }\end{array} & \text { electric } & \text { circuit } \\
\end{array}$ & $\begin{array}{l}\text { No specific requirements, } \\
\text { emission-related fault }\end{array}$ \\
\hline Comprehensive parts & $\begin{array}{l}\text { Functional diagnosis } \\
\text { circuit electric } \\
\text { non-functional parts) }\end{array}$ & $\begin{array}{l}\text { No specific requirements, } \\
\text { emission-related fault }\end{array}$ \\
\hline $\begin{array}{l}\text { Other emission control } \\
\text { systems }\end{array}$ & Function diagnosis & $\begin{array}{l}\text { No specific requirements, } \\
\text { emission-related fault }\end{array}$ \\
\hline
\end{tabular}

In view of the above problems, this paper conducts experimental research on the fuel system faults in American Standard OBDII, studies the influence degree and specific test methods of different types of faults on vehicle exhaust emissions, and provides the basis for the development of enterprise diagnosis technology and government supervision.

\section{Test vehicles}

In order to carry out the OBD fault diagnosis test of the vehicle, it is necessary to use the relevant test equipment of the vehicle emission test room, including the drum, full flow exhaust emission analyzer. In addition, it is necessary to use tools such as fault diagnosis instrument and fault information reading equipment to read and record various state parameters of vehicle fault. See Table 2 for basic parameters of relevant equipment.

Table 2. Parameters of test equipments.

\begin{tabular}{c|c|c|c}
\hline Eqiupment & Type & Country & Parameters \\
\hline
\end{tabular}




\begin{tabular}{c|c|c|c}
\hline Dyno & AVL & Austria & Inertia simulation range: $454 \sim 6345 \mathrm{~kg}$ \\
\hline Analyzer & $\begin{array}{c}\text { HORIBA } \\
7200 \mathrm{H}\end{array}$ & Japan & THC, CO, NOX, CO2, CH4, PM, PN, N2O \\
\hline Chamber & WEISS & German & Temperature simulation: $-40^{\circ} \mathrm{C} \sim 60^{\circ} \mathrm{C}$ \\
\hline Scan tool & X431 & China & OBDII, EOBD \\
\hline Fault device & CarDAQ & USA & OBDII, EOBD \\
\hline
\end{tabular}

The requirements of American OBDII standard are unique, which is quite different from European EOBD and China's national five OBD. In order to carry out the test and Research on the fuel system fault diagnosis project, it is necessary to find the vehicles that meet the OBDII standard first, and only the vehicles sold to the American market can fully meet the requirements of OBDII standard, that is, only American standard vehicles can complete the research work of this project.

For this reason, through cooperation with two Japanese enterprises and one American enterprise, three vehicles that meet the U.S. sulev30 emission standard have been found in the U.S. market through these companies. The specific parameters are shown in Table 3.

Table 3. Parameters of test vehicles.

\begin{tabular}{c|c|c|c}
\hline Parameter & Japanese Car 1 & Japanese Car 2 & American Car \\
\hline Model & Car & Car & SUV \\
\hline Fuel & $95 \#$ & $95 \#$ & 95\# \\
\hline Spray & GDI & GDI & GDI \\
\hline Displacement (L) & 2.5 & 1.6 & 2.0 \\
\hline Emission level & SULEV30 & SULEV30 & SULEV30 \\
\hline Catalytic converter & Yes & Yes & Yes \\
\hline Oxygen sensor & Yes & Yes & Yes \\
\hline VVT & No & Yes & Yes \\
\hline EGR & Yes & No & No
\end{tabular}

\section{Test method}

\subsection{Fault implantation method}

OBDII standard requires many faults and types, and different fault simulation methods are different. For example, some faults can be simulated by replacing fault hardware, some faults can be simulated by fault simulator, and some faults are difficult to be simulated by the above two methods, such as cold start emission reduction strategy, VVT and fuel system. At this time, with the consent of the regulatory structure, the engine calibration tool can be used to modify the calibration parameters in the ECU to achieve the simulation of such faults. See Table 4 for the fault simulation mode adopted in the fuel system fault demonstration test in this project.

Table 4. Various fault insertion methods.

\begin{tabular}{l|l|l|l}
\hline Fault type & Japanese Car 1 & Japanese Car 2 & American Car \\
\hline Fuel system-lean & Software & X & Software \\
\hline Fuel system-rich & $\mathrm{X}$ & Fault fuel injector & Software \\
\hline Fuel & $\mathrm{X}$ & Fault fuel injector & Software \\
\hline
\end{tabular}


system-imbalance

\subsection{Test Procedures}

For satisfying a variety of fault diagnosis conditions, vehicles may necessarily operate for a certain amount of time in accordance with various test cycles and modes prior to any fault demonstration test so that the fault diagnosis functions may be triggered ${ }^{[1,8-10]}$. The cycles and operation modes for the fault demonstration tests in this study are shown in Table 5, where "General Method" refers to "preconditioning: UDDS, and test: FTP75"; as for some special diagnostics, OBD II allows those companies to flexibility regulate the test procedures based on General Method in accordance with their own diagnosis logics; for example, those cycles such as HWFET and US06 are added for stabilization of emissions or the diagnosis strategy in preconditioning cycles. In addition, MILs may not be activated in FTP75 cycles as for some faults; and companies are allowed to add UC cycles for first activation of MILs and then OBD emission compliance may be measured and verified by means of operation of faulty FTP75 emission tests. " $\mathrm{X}$ " in Table 5 represents no such test item in this study.

Table 5. OBD test procedures.

\begin{tabular}{|c|c|c|c|}
\hline Fault type & JAPANESE CAR 1 & JAPANESE CAR 2 & American Car \\
\hline Fuel system-lean & $\begin{array}{l}\text { Preconditioning: } \\
\text { additional } \\
(@ 60 \mathrm{~km} / \mathrm{h}) \text { for } 10 \\
\text { minutes }+ \text { operation } \\
(@ 100 \mathrm{~km} / \mathrm{h}) \text { for } 10 \\
\text { minutes }+ \text { idle operation } \\
\text { for } 10 \text { minutes }\end{array}$ & $X$ & $\begin{array}{l}\text { Preconditioning: } \\
\text { additional HWFET }\end{array}$ \\
\hline Fuel system-rich & $\mathrm{X}$ & $\begin{array}{l}\text { Preconditioning: } \\
\text { additional HWFET and } \\
\text { US06 }\end{array}$ & $\begin{array}{l}\text { Preconditioning: } \\
\text { additional HWFET }\end{array}$ \\
\hline $\begin{array}{l}\text { Fuel } \\
\text { system-imbalance }\end{array}$ & $\mathrm{X}$ & $\begin{array}{l}\text { Preconditioning: } \\
\text { additional HWFET and } \\
\text { US06; } \\
\text { Tests: UC and FTP75 }\end{array}$ & $\begin{array}{l}\text { Preconditioning: } \\
\text { additional HWFET and } \\
\text { US06; } \\
\text { Tests: UC and FTP75 }\end{array}$ \\
\hline
\end{tabular}

It can be seen from the above table that the hwfet, US06 and UC cycles with higher speed and greater acceleration are used for the fuel system cylinder to cylinder heterogeneity, lean fuel system mixture and rich fuel system mixture. Only under these cycles can the various conditions required for diagnosis be achieved. Similar methods are also introduced into the latest six OBD standards in China, which facilitates enterprises to adopt more flexible and diverse diagnostic principles to meet the requirements of the standards.

\section{Analysis of test results}

In the process of fault diagnosis of fuel system, different enterprises will adopt different fault diagnosis methods. In addition, due to the different hardware configuration of fuel injector and oxygen sensor in the vehicle fuel system, the final fault code of fuel system is also different. But generally, the fuel system faults include the following categories. 
Table 6. Fuel system faults.

\begin{tabular}{c|c|c}
\hline DTC & Fault meaning & Fault insertion methods \\
\hline P0171 & Front feedback - lean & Software or replace the small hole injector \\
\hline P0172 & Front feedback - rich & Software or replace the large hole injector \\
\hline P2096 & Back feedback - lean & Software or make A/F signal smaller \\
\hline P2097 & Back feedback - rich & Software may make A/F signal larger \\
\hline P219C-P21 & Imbalance - all cylinders & Software or change the injector hole size of a \\
9F & cylinder \\
\hline P219A & Imbalance - cylinder 1,3, & Software or change the injector hole size of a \\
& 5 & cylinder \\
\hline P219B & Imbalance - cylinder 2, 4, & Software or change the injector hole size of a \\
& 6 & cylinder \\
\hline
\end{tabular}

\subsection{Fault emissions of fuel system rich}

In this paper, the fault tests (corresponding to the fault code p0171) of the mixture concentration in the fuel system of Japanese car 2 and American car are carried out respectively. Japanese car 2 has replaced four special fuel injectors with larger injection holes, so that under the same injection control signal, the actual fuel injected into each cylinder is $30 \%$ more than that under normal conditions, so as to simulate the failure of the mixture concentration in the fuel system. American cars directly modify the fuel injection parameters in the engine controller to increase the actual fuel injected into each cylinder by $30 \%$.

It can be seen from the test results that due to the failure, the mixture in the cylinder becomes rich and the combustion is not sufficient, which makes the $\mathrm{CO}$ and NMHC in the pollutants emitted by the vehicles increase by 3.6 and 1.8 times respectively, and the NMHC emissions increase by 5 and 3.8 times respectively. Due to the lack of combustion oxygen, the NOx emission of the two vehicles does not change much.

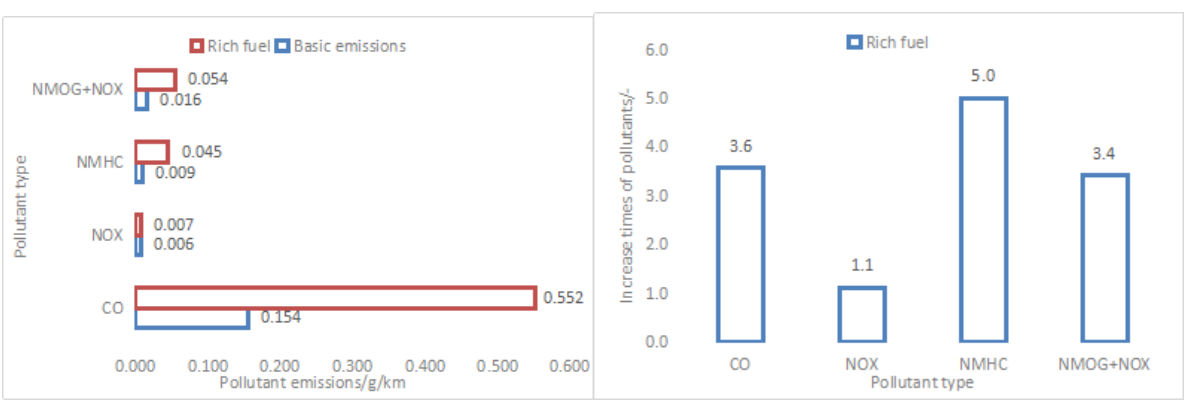

Fig. 1. Fuel rich emission results for Japanese Car 2. 


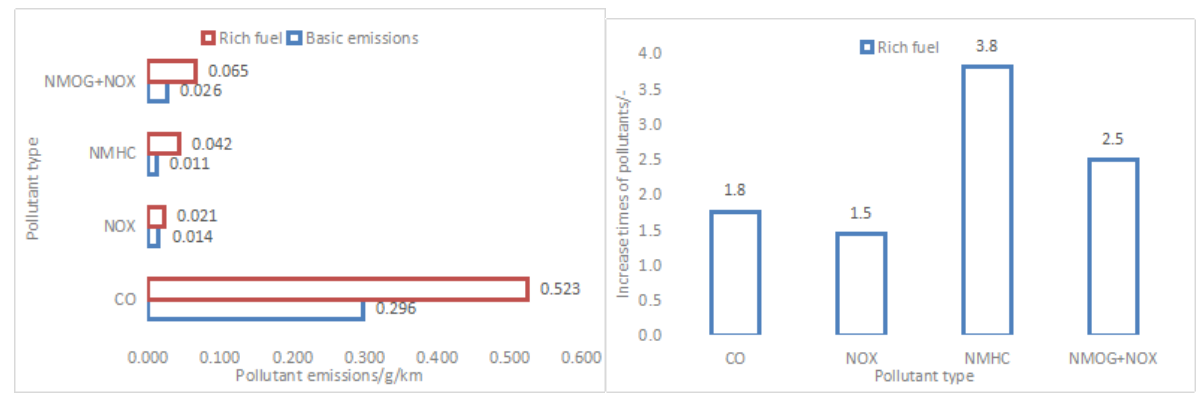

Fig. 2. Fuel rich emission results for American Car.

\subsection{Fault Emissions of Fuel System Lean}

The lean mixture fault is generally caused by the blockage of engine injector or the failure of front oxygen sensor. When these faults occur, the actual fuel injected into the cylinder is less than that under normal conditions, and the air intake does not change, which makes the mixture lean. In this paper, the same fault simulation method is used for both vehicles. The fault is simulated by modifying the fuel injection control parameters in the controller, so that the mixture concentration is reduced by $30 \%$ compared with the normal situation.

It can be seen from the test results that the NOx pollutants of the two vehicles increased by 5 and 3 times respectively, which is the most serious pollutant of emission deterioration. $\mathrm{CO}$ and NMHC pollutants increased about 2 times. The reason is that the excess air coefficient deviates from the theoretical air-fuel ratio, the conversion efficiency of the catalytic converter is reduced, and the pollutants will increase in case of lean fuel mixture failure. At the same time, the oxygen in the mixture in the cylinder is sufficient, the mixture can be fully burned, resulting in more NOx emissions.

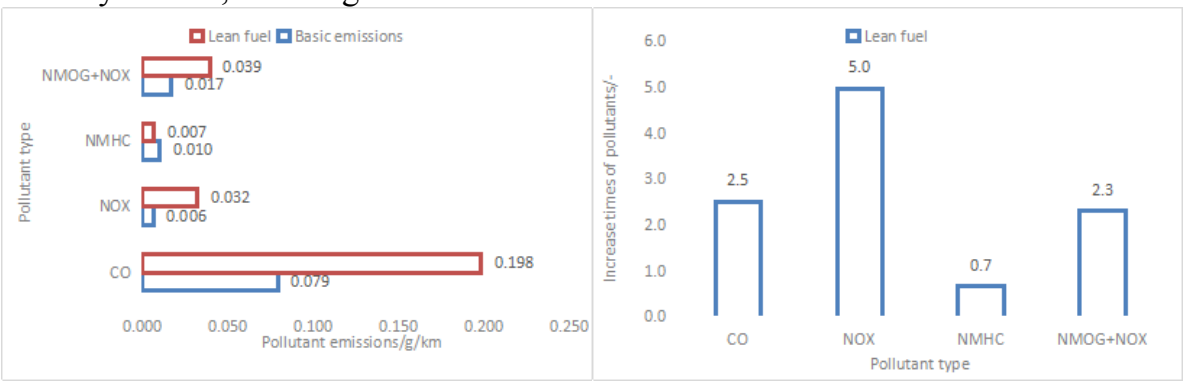

Fig. 3. Fuel lean emission results for Japanese Car 1.
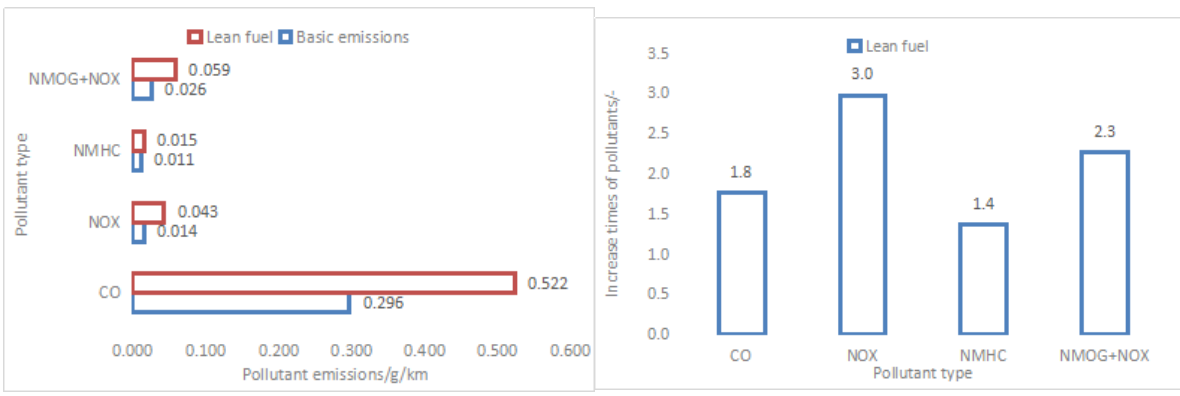

Fig. 4. Fuel lean emission results for American Car. 


\subsection{Fault emissions of imbalance}

In the fuel system, the fault of imbalance mixture between cylinders is a kind of fault monitoring of different mixture concentration between cylinders. When only the injector in a certain cylinder is blocked, or the length of exhaust pipe is not designed properly, or the position of oxygen sensor is not arranged properly, the air-fuel ratio of each cylinder measured by the oxygen sensor will be greatly different, resulting in the imbalance failure between cylinders.

There are two kinds of methods commonly used to diagnose the non-uniform fault between cylinders. One is diagnosis through A/F sensor. Since the combustion of mixture in different cylinders is carried out in time, the time of mixture arriving at the A/F sensor after combustion in each cylinder is also separated. By identifying the corresponding parts of each cylinder in the $\mathrm{A} / \mathrm{F}$ signal and processing the signal, the cylinder with imbalance fault between cylinders can be analyzed. One is to determine whether the fault exists by analyzing the crankshaft signal. When the mixture of a certain cylinder is abnormal, the corresponding crankshaft signal will also be abnormal. Because of the different diagnosis principle, the accuracy of the two methods is also different. Because the first method can measure the mixture accurately, it can diagnose two kinds of faults, one is imbalance concentration between cylinders, the other is imbalance dilution between cylinders. In the second method, because the original signal is the crankshaft speed signal, when the mixture is lean, the signal drops, and there is fault feature, but when the mixture is rich, the signal changes little, and the fault feature is not obvious. In order to increase the accuracy of diagnosis, the two methods are usually used at the same time. The first method is only used when the mixture between cylinders is rich. In this paper, two test vehicles use this strategy.

It can be seen from the emission results that the US car simulated the non-uniform concentration fault between cylinders. Due to the reduction of the conversion efficiency of the catalyst and the inadequate combustion, $\mathrm{CO}$ and NMHC increased by about three times, and NOx increased by 2.5 times. Japanese car 2 simulated the imbalance lean fault between cylinders. Due to the reduction of conversion efficiency and high combustion temperature, NOx increased by 7.5 times, and CO and NMHC also increased to a certain extent.

Because of the complexity of the non-uniformity fault between cylinders and the high requirement of the engine structure design, there is no requirement of the fault diagnosis in the sixth emission standard of light vehicles. However, due to its great impact on emissions, it should be considered to increase the diagnostic requirements in China's future OBD standards, and also clearly put forward the fault mode that needs to be diagnosed, and at the same time, adopt stricter fault emission limits, so that the OBD system can find faults as early as possible. As the intake system, exhaust system, oxygen sensor position and EGR function of engine will affect the diagnosis of cylinder to cylinder non-uniformity fault, it will take 2-5 years for general enterprises to meet the diagnosis requirements of OBD standard for cylinder to cylinder non-uniformity fault. From the early stage of engine structure design, enterprises should consider the needs of fault diagnosis, reasonably design various structures and parameters, and propose Improve the technical level of fault diagnosis. 


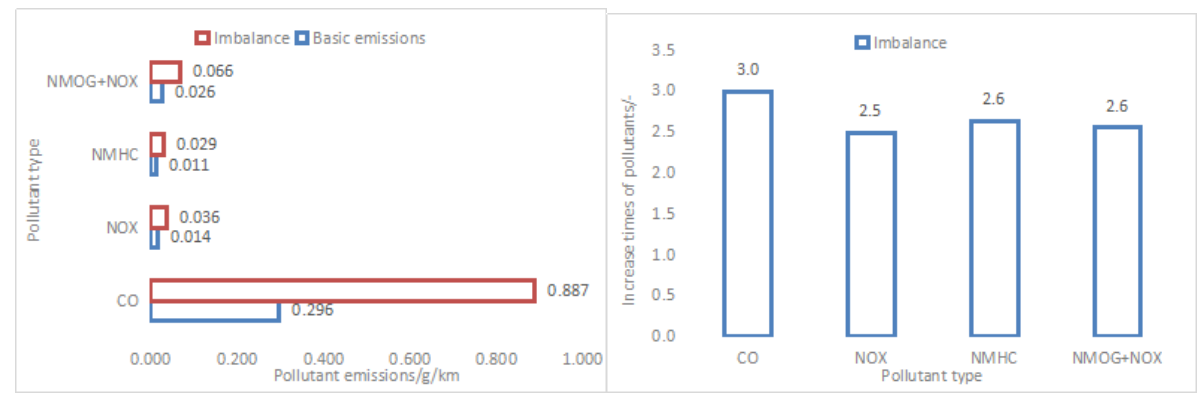

Fig. 5. Imbalance emission results for American Car.

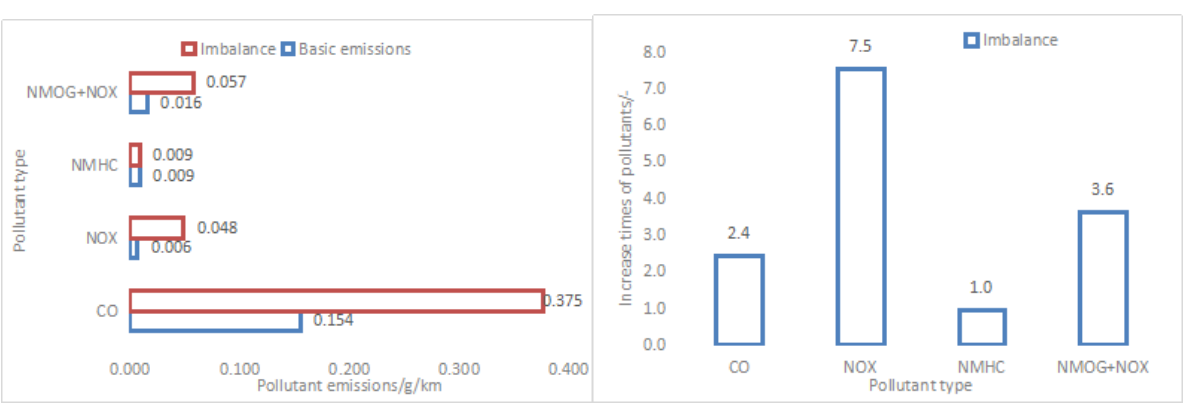

Fig. 6. Imbalance emission results for Japanese Car 2.

In addition to the above three types of fuel system faults, the failure of all sensors and actuators designed in the fuel system will lead to the deviation of the mixture concentration in the fuel system and the deterioration of engine emissions. Therefore, these fault diagnosis items should be further strengthened in China's future OBD standards, and the fault criteria for each type of fault should be clearly defined, so that the functions of all systems, components and strategies in the engine fuel system can be monitored by the OBD system, and the emission limit requirements for OBD faults should be reduced, and the existence of faults should be found in time, Reduce the increase of emissions caused by vehicle failure and protect the atmospheric environment.

\section{Conclusions}

Based on the research of OBDII standard and the test of exhaust emission of the fuel system fault diagnosis project in OBDII based on American Standard test vehicle, it can be concluded as follows:

1) The failure of rich mixture and imbalance concentration between cylinders will increase the emission of $\mathrm{CO}$ and NMHC pollutants by 3-5 times, and the NOx will also increase to a certain extent. The main reasons for the increase of emission are the reduction of conversion efficiency and inadequate combustion of the catalyst.

2) The failure of lean mixture and imbalance lean between cylinders will increase NOx emission by 4-7.5 times, and $\mathrm{CO}$ and NMHC will also increase to a certain extent. The main reasons for the increase of emission are the reduction of conversion efficiency of catalyst and high combustion temperature.

3) There are many kinds of fault types in the fuel system. A single test cycle or test process can not make all fault types successfully realize fault diagnosis. Because different trigger conditions of fault diagnosis are different, different types of fault types need to adopt different test cycles and processes to meet all the conditions required for diagnosis. 
Therefore, it is necessary to combine the specific situation of the enterprise and It is recommended to develop a flexible testing process.

4) Emission reduction may not be achieved only based on the OBD system. If the fault is found out and MIL is ON while any vehicle fault occurs and emissions rise, it will be only prompted that the vehicle shall be maintained in time. If the user does not perform maintenance to the fault, emissions may not be controlled. Thus, requirements of OBD standards shall be optimized; moreover, the actual usages (such as I/M, on-road inspection, random inspection) of the OBD system shall be effectively monitored. Emissions may be actually under control by means of the OBD system.

This work was financially supported by the National Key Research and Development Program of China (2018YFE0106800), the Construction of Public Service Platform for Vehicle Emission/Energy Consumption Information System(Improvement of public service capacity of Industrial Technology Foundation 2018), the Integrated Technology of Particulate Matter Capture and Clean Emission for Gasoline Vehicles Projects (No.: 2017YFC0211004 and 2017YFC0211005).

\section{References}

1. CARB .Title13, California Code of Regulations, Section 1968.2, Malfunction and Diagnostic System Requirements for 2004 and Subsequent Model-Year Passenger Cars, Light-Duty Trucks, and Medium-Duty Vehicles and Engines.

2. CARB .Title13, California Code of Regulations, Section 1968.5, Enforcement of Malfunction and Diagnostic System Requirements for 2004 and Subsequent Model-Year Passenger Cars, Light-Duty Trucks, and Medium-Duty Vehicles and Engines.

3. GB18253.5-2013, Limits and measurement methods for emissions from light-duty vehicles China 5 stage) [S]. State Environmental Protection Administration, General Administration of Quality Supervision, 2013.

4. LU Jun, ZHENG Hong-wu. The Statement of Vehicle's OBD System [J]. Equipment Manufacturing Technology. 2012, (8): 135-138.

5. Pang Chengli. Development and Applications of On-Board Diagnostic System (OBD) [J]. Automobile Maintenance. 2011, (9): 40-42.

6. Pan Peng, Yan Fuwu, Fang Maodong. Current situations and development trends of OBD system [J]. MARINE ENERGY SAVING.2007(5):37-39.

7. NIU Xiaoxiao. Liu Qiang. The Overview of On-Board Diagnostics System [J]. Automobile Parts. 2010 (4): 73-76

8. Gardetto E, BagianT, Lindner J. High-mileage study of on-board diagnostic emissions [J]. Journal of the Air \& Waste Management Association. 2005, 55 (10):1480-1486.

9. Daniel R, Brooks T, Pates D. Analysis of US and EU Drive Styles to Improve Understanding of Market Usage and the Effects on OBD Monitor IUMPR [J]. SAE Technical Paper.2009,doi:10.4271/2009-01-0236.

10. Yun Hyunjeong, Lee Shinkyung ,Kwon Ohcheon .Vehicle generated data exchange protocol for remote OBD inspection and maintenance [J].Computer Sciences and Convergence Information Technology(ICCIT).2011(6):81-84. 